\title{
Children's Understanding and Experience of Conditional Promise with Mothers: Focused on Children's Trust in Mothers and Self-Regulation
}

\author{
Ah-Reum Han ${ }^{1}$, Sae-Young Han ${ }^{2}$ \\ Lecturer, Department of Human Development \& Family Studies, Duksung Women's University, Seoul, Korea ${ }^{1}$ \\ Professor, Department of Child Development \& Intervention, Ewha Womans University, Seoul, Korea ${ }^{2}$ \\ 어머니와의 조건약속에 대한 아동의 이해와 경험: 어머니에 대한 신뢰감 및 자 \\ 기조절능력과의 관계를 중심으로 \\ 한아름 ${ }^{1}$, 한세영 ${ }^{2}$ \\ 덕성여자대학교 아동가족학과 강사 ${ }^{1}$, 이화여자대학교 아동학과 교수 ${ }^{2}$
}

Objectives: The main purpose of the study was to examine children's understanding of conditional promise fulfillment and violation, and emotional responses to the promise parties (study 1). In addition, this study investigated the indirect effect of children's experience of mothers' promise fulfillment and violation on self-regulation through their trust in their mothers (study 2).

Methods: The participants of this study were 122 children (4-7 years of age) and their mothers. Children were interviewed individually and their mothers completed questionnaire about children's self-regulation. The collected data were analyzed using frequency analysis, chi-square test (study 1), correlation analysis and regression analysis (study 2) with SPSS 21.0.

Results: In Study 1, there was a significant difference in children's understanding of promise fulfillment/ violation and emotional response to promise parties depending on age and violation events. In Study 2, we observed an indirect effect of children's perception of mothers' promise fulfillment and violation on children's self-regulation through trust in mothers were significant.

Conclusion: This research suggested that it is necessary to consider developmental difference in children's understanding of fulfillment and violation of conditional promise. Morevoer, the mothers' promise-fulfillment behavior could be important to increase children's trust in their mothers and their self-regulation. The results of the this study may be used as an effective resource in the educational field and in parent education programs.

Keywords: conditional promise fulfillment and violation, understanding of promise, trust, selfregulation

\section{Introduction}

약속이행을 이행하는 것은 대인관계에서 상호신뢰를 형성하 고 사회질서를 유지하는 중요한 행위로, 도덕적 태도의 한 측

Corresponding Author: Sae-Young Han, Professor, Department of Child Development \& Intervention, Ewha Womans University, 52, Seodaemun-gu, Seoul 03760, Korea

E-mail: evenhow@ewha.ac.kr
면으로 간주되어 왔다. 약속을 이행함으로써 상대방은 약속을 한 사람을 신뢰할 수 있는 반면에 약속을 위반하는 모습은 상 대방으로 하여금 불신과 대인관계 문제의 원인이 될 수 있다. 약속은 두 명 이상의 사람들 간의 관계에서 이루어지며, 상대

(C)The Korean Association of Child Studies

This is an Open Access article distributed under the terms of the Creative Commons Attribution Non-Commercial License (http:// creativecommons.org/licenses/by-nc/4.0) which permits unrestricted noncommercial use, distribution, and reproduction in any medium, provided the original work is properly cited. 
방에게 자신이 미래에 어떠한 행위를 할 것임을 전달하는 언 어적 상호작용으로(Searle, 1969), 약속을 이행하는 것은 대인 관계를 유지하고 상호 신뢰를 형성하는 데 중요한 역할을 한 다고 볼 수 있으며, 인간관계에서 지켜야 하는 사회적 규범으 로서 도덕적 행위라 할 수 있다.

약속이행과 위반은 사회적 관계 속에서 이루어지며, 아동 은 초기 사회적 관계인 어머니와의 관계에서 어릴 때부터 무 수히 많은 약속을 경험하게 된다. 실제 일상에서 “이번 주말 에 놀이동산에 갈게." 또는 "다음 생일에는 갖고 싶었던 장난 감을 사줄게.”와 같이 어머니가 자녀에게 일방적으로 약속을 이야기하는 경우도 있지만, "이번 시험을 잘 보면 갖고 싶었던 것을 사줄게." 또는 "동생을 잘 데리고 있으면, 다녀와서 용돈 을 줄게."와 같이 자녀가 어떠한 행동을 하는 것을 전제로, 그 행동에 대한 보상을 제시하는 형식의 조건약속이 이루어지기 도 한다. 그러나 어머니가 자녀에게 한 약속을 무심코 지나가 거나, 비일관적으로 약속을 지키는 모습을 보이게 되면 점차 자녀는 약속의 중요성에 대한 인식을 못하게 되어 어머니가 제안하는 약속을 무시하거나 가볍게 여길 수 있고, 심지어 약 속을 어기는 행동 또한 모방할 위험도 있다. 뿐만 아니라 어머 니가 자신과의 약속을 중요하게 인식하지 않고 약속을 위반한 경험은 어머니와 자녀와의 관계에도 부정적인 영향을 미칠 수 있다. 이와 같이 약속이행이 갖는 중요성에도 불구하고, 발달 적 관점에서 아동이 약속이행과 위반에 대해 어떻게 이해하고 있으며, 이러한 이해능력을 기초로 하여 일상생활에서 겪게 되는 약속이행과 위반의 경험은 어떠한지, 그리고 나아가 약 속이행과 위반의 경험이 어떠한 발달적 결과를 가져오는지에 대해서는 주목받지 못하고 있다.

발달적 관점에서 아동의 약속이행 및 위반에 접근한 연 구들은 소수에 불과하여 아동의 약속이행과 위반에 관한 소 수의 연구들 또한 아동의 약속이행과 위반의 이해능력에 초 점을 두고 가상의 약속 상황에서 주인공들의 약속 이행과 위반 여부를 이해할 수 있는지를 주로 살펴보았다(Barrett, Keller, Takezawa, \& Wichary, 2007; Chin \& Lin, 2018; Keller, Gummerum, Tien Wang, \& Lindsey, 2004). 그 결과 4세 이상의 아동도 약속상황에 대해 약속과 이행여부를 판별할 수 있다고 보고한 바 있는데(Barrett et al., 2007; Chin \& Lin, 2018; Keller et al., 2004), 이를 토대로 가상의 약속상황에서 이행과 위반 여 부를 이해할 수 있는 아동은 실제 일상생활에서 어머니와 이 루어지는 약속상황에서도 어머니의 약속의 이행과 위반여부 를 판단할 수 있을 것으로 예측해 볼 수 있다. 이에 본 연구에 서는 어머니와의 약속경험이 어머니와 자녀와의 관계, 자녀의
발달에 어떠한 영향을 미치는지 살펴보기에 앞서 먼저 아동이 조건 약속의 이행과 위반에 대해 이해하는 능력이 충분히 발 달하였는가를 살펴보고자 하였다. 연구 1 에서는 어머니와 자 녀간의 약속이행 및 위반에 대한 아동의 이해능력을 살펴보았 으며, 연구 2에서는 어머니의 약속이행 및 위반행동에 대한 실 제 경험이 아동의 어머니에 대한 신뢰감을 통해 자기조절능력 에 어떠한 영향을 미치는지 규명하고자 함으로써 어머니의 약 속이행 및 위반 행동이 아동에 미치는 발달적 영향을 검증하 고자 하였다.

\section{Study 1}

연구 1 에서는 약속 중 특히 조건약속에 대한 아동의 이해능력 에 주목하였다. 기존의 대부분의 선행연구에서는 어머니-자 녀 간의 약속상황을 다룰 때 조건 약속을 따로 구분하여 살펴 보지 않았으나(Choi, 2002; Kim, 1989; Woo \& Choi, 2001), 조 건약속에는 약속자와 피약속자 상호간의 약속을 이행해야할 의무가 포함되어 있을 뿐만 아니라, ' 하면, 한다.'와 같은 조건문 형식으로 구성되어 조건문 형식을 이해하는 인지적 능 력이 선행되어야 한다는 전제를 담고 있다. 즉 아동이 조건약 속의 이행과 위반을 이해하는지를 살펴봄으로써 약속에 포함 된 의무를 이해할 수 있는 능력과 조건문 형식을 이해할 수 있 는 인지적 능력이 발달하였음을 함께 파악해 볼 수 있다. 또 한, 타인의 위반상황을 이해하고 상황을 단서로 타인의 정서 적 반응을 이해하는 능력은 실제 생활에서도 어떤 행동이 옳 은 행동인지를 이해할 수 있는 능력과 한 사람의 행동이 타인 에게 정서적 반응을 유발하는 영향력이 있음을 이해하는 능 력이 발달하였음을 보여줄 수 있다. 도덕발달 연구자들은 어 린 유아들도 도덕적 개념을 이해하고, 위반 행위에 대해서도 옳고 그름을 판단할 수 있을 뿐만 아니라(Dias \& Harris, 1990; Hawkins, Pea, Glick, \& Scribner, 1984), 도덕적 위반자와 피해 자의 정서도 이해할 수 있다고 보고하고 있다(Trabasso, Stein, \& Johnson, 1981; Nunner-winkler \& Sodia, 1988). 이러한 맥락 에서 아동이 약속이행과 위반으로 인한 약속 당사자(약속이 행자, 약속위반자, 약속위반으로 인한 피해자)의 정서적 반응 을 이해하는 것을 통해, 약속이행이 옳은 행동이고 약속위반 이 옳지 않은 행동임을 판단할 수 있는 능력을 갖고 있음을 파 악할 수 있다. 뿐만 아니라 약속을 위반하는 행동이 상대방에 게 부정적 영향을 미칠 수 있음을 이해하는 인과적 추론능력 이 발달하였고, 약속이행과 위반이 갖는 도덕적 가치를 내면 화하였음을 파악하는 지표가 될 수 있다는 점에서 중요하다. 
따라서 본 연구 1 에서는 조건약속 상황에서 약속 당사자(약속 이행자, 약속위반자, 약속피해자)의 정서적 반응에 대한 이해 능력도 아동의 약속이행 및 위반 이해능력에 포함하여 살펴보 고자 하였으며, 아동이 어머니와 자녀와의 약속 상황에서 약 속이행과 위반을 어떻게 이해하는지 그리고 그에 대한 정서적 반응을 어떻게 이해하는지 규명해보고자 하였다.

\section{연구문제 1}

어머니-자녀 간의 약속이행 및 위반에 대한 아동의 이해는 연 령에 따라 차이가 나는가?

\section{연구문제 2}

어머니-자녀 간의 약속이행 및 위반 당사자의 정서적 반응에 대한 아동의 이해는 연령에 따라 차이가 나는가?

\section{Methods}

\section{연구대상}

본 연구의 대상은 수도권에 소재하는 유아교육기관과 초등 학교에 다니는 만 4세와 만 5세 각각 30명, 만 6세와 만 7세 각 각 31 명 총 122 명(남아 60 명, 여아 62명)을 대상으로 하였다. 본 연구에서 만 4-7세 아동을 연구대상으로 선정한 이유는 약 속이행과 위반을 이해하기 위해서는 의무와 조건문을 이해하 는 논리적인 추론능력, 타인의 감정을 이해하는 능력이 요구 되는데, 만 4세 이상의 아동은 의무가 포함된 상황을 이해할 수 있고(Nakamichi, 2004), 논리적인 추론이 가능하고 위반상 황을 이해할 수 있으며(Dias \& Harris, 1990), 다른 사람의 정서 를 이해하는 시기(Nunner-winkler \& Sodia, 1988)라는 선행연 구에 근거하였다. 또한 만 4 세 시기의 아동은 약속에 대한 이 해수준이 낮고 제한적으로 약속을 이해하며, 만 7세 이후가 되 면서 점차 약속위반행동을 구분한다는 결과가 보고되는 반면 (Astington, 1988), 만 4세 이후의 아동도 약속위반 상황을 이해 하는 것으로 보고되었다(Keller et al., 2004). 이처럼 만 4세부터 약속이행과 위반에 대한 이해가 시작되나 이해의 폭에 대해서 는 학자들의 견해차이가 있어, 이 시기 아동의 약속이행과 위 반, 정서적 반응에 대한 재검증이 필요하다고 판단하여 만 4-7 세 아동을 연구대상으로 선정하였다.

\section{연구도구}

아동의 약속이행 및 위반이해 과제

아동의 약속 이행 및 위반에 대한 아동의 이해능력을 측정하 기 위해 기존의 선행연구(Barrett et al, 2007; Keller et al, 2004) 에서 사용한 도구를 우리나라의 아동에게 적용할 수 있도록 수정, 보완하여 사용하였다. 선행연구에서 사용된 상호간의 약속은 “주인공 아동이 2주 동안 집을 깨끗이 청소하면, 어머 니가 크리스마스 선물로 자전거을 사준다.", “주인공 아동이 정원을 청소하면 어머니가 비디오게임을 하게 해준다.”의 내 용으로 구성되어 있다. 본 연구에서는 선행연구에서 사용한 도구를 우리나라 현실에 적합하도록 "주인공 아동이 방청소 를 하면, 아동이 갖고 싶은 장난감 선물을 어머니가 사준다.” 로 수정하여 사용하였으며, 선행연구와 마찬가지로 상호 간의 약속이 이루어졌음을 전제로 하였다(bilateral promise). 아동이 약속이행 및 위반상황 이야기 내용을 이해하도록 돕기 위해 상황이야기가 표현된 그림카드를 함께 제시하였다. 본 연구에 사용되는 그림의 종류는 4 가지로 방이 청소된 그림, 방이 청소 되지 않은 그림, 아동이 장난감 선물을 받는 그림, 아동이 장난 감 선물을 받지 않은 그림이다. 그림카드 안에는 4가지 그림을 2 개씩 조합하여 총 4 가지 약속이행 및 위반상황을 나타내는 4 가지 카드를 구성하였다(Figure 1). 구체적인 과제실시 절차는 다음과 같다. 먼저, 약속이행 및 위반 이해능력을 확인하기 위 해 아동에게 약속이행과 위반 이야기를 들려주었다. 그 후, 그 림카드 1 (주인공 아동이 방을 청소하고, 어머니가 장난감 선 물을 준 그림)부터, 그림카드 2 (주인공 아동이 방을 청소하 고, 어머니가 장난감 선물을 주지 않은 그림), 그림카드 3 (주 인공 아동이 방을 청소하지 않고, 어머니가 장난감 선물을 준 그림), 그림카드 4 (주인공 아동이 방을 청소하지 않고, 어머니 가 장난감 선물을 주지 않은 그림)를 제시하였다. 4 가지 그림 카드를 보여주면서 주인공 아동과 어머니와의 약속이 이행되 었는지, 위반하였는지 질문한 이후에 주인공 아동 또는 어머 니가 약속을 이행하였는지, 위반하였는지 질문하였다. 마지막 으로 약속 이행 및 위반상황에서 약속 이행자와 위반자, 피해 자가 느끼는 기분이 어떠한지 질문하였다.

본 연구에서 사용된 약속 이행 및 위반 이야기는 상호 간의 동의하에 이루어진 약속(social contract)이라는 점을 전제로 하 였다. 즉 한사람이 약속을 제안하기는 하였으나, 두 사람 모두 기대되는 행동을 이행할 것임을 약속한 것이며, 기대되는 행 동을 이행한 결과 원하는 이익을 얻을 수 있는 것으로 보았다. 


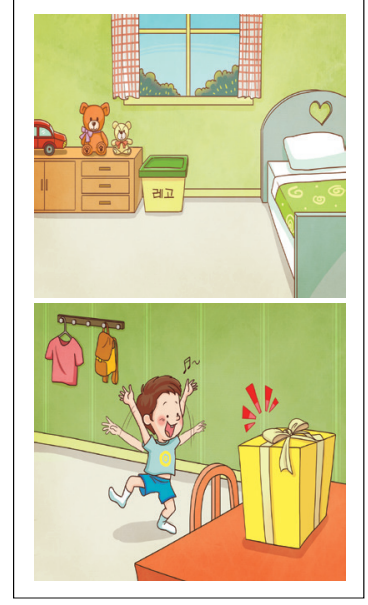

$p, q$

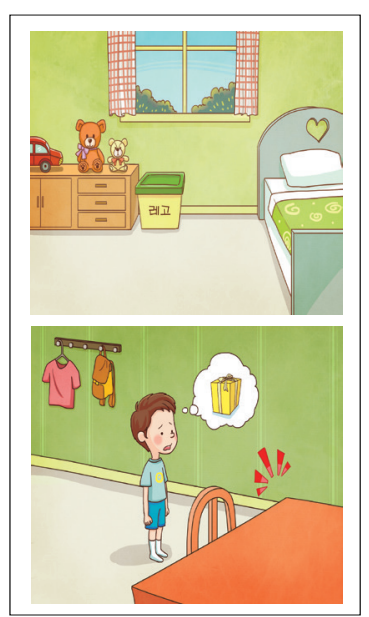

$p$, not q

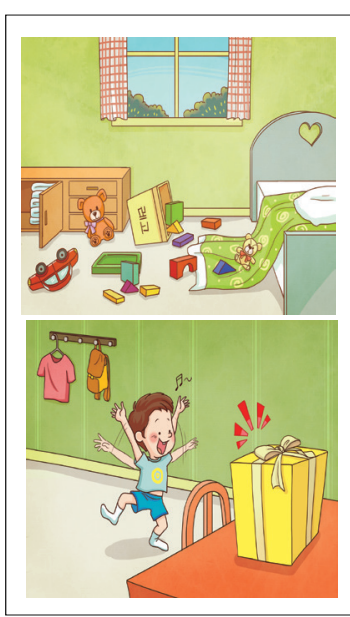

not $p, q$

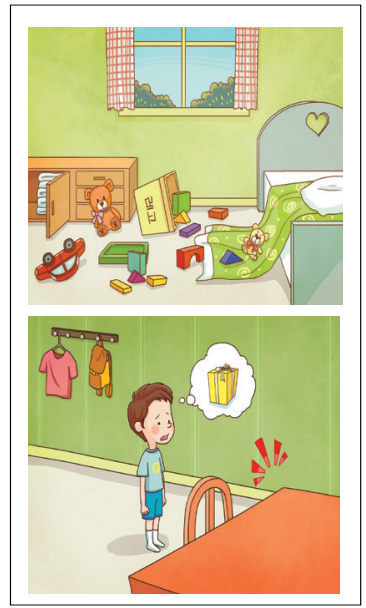

not $p$, not $q$

Figure 1. Four picture cards.

먼저 약속이행 및 위반에 대한 이해능력의 경우, (1) p, q (아동 이 방청소를 하고, 어머니가 장난감을 사준다)는 아동과 어머 니 모두 약속을 이행한 것이다. (2) p, not q (아동이 방청소를 하지만, 어머니는 장난감을 사주지 않았다)는 아동은 약속을 이행한 반면에, 어머니는 약속을 위반한 것이다. (3) not $\mathrm{p}, \mathrm{q}$ (아이는 방청소를 하지 않았지만, 어머니는 장난감을 사준다) 는 아이는 약속을 위반하고 어머니도 위반한 것이다. 마지막 으로 (4) not p, not q (아이는 방청소를 하지 않고, 어머니는 장 난감을 사주지 않는다)는 아동은 약속을 위반했으나, 어머니 는 약속을 이행한 것이다.

다음으로, 약속위반의 이행자, 위반자와 피해자에 대한 정 서적 반응의 경우, 아동이 즐겁다, 좋다 등으로 응답한 경우에 는 긍정적인 정서로, 화가 난다, 기분이 나쁘다, 미안하다, 실 망스럽다 등으로 응답한 경우에는 부정적인 정서로 구분하였 다. Keller 등(2004)의 선행연구에 근거하여 모르겠다, 좋기도 하고 나쁘기도 하다와 같은 양가적인 응답도 부정적인 정서에 포함하였다.

\section{연구절차}

본 연구를 진행하기에 앞서 연구자가 소속된 기관에서 연구 제반과정에 대한 IRB승인을 받았으며(IRB No. ewha-2019090017-01), 본조사에 앞서 예비조사를 실시하여 연구도구의 적 절성 및 소요시간을 점검한 후 본조사를 위한 질문지를 최종 적으로 선정하였다. 본 조사는 2019년 10월 2020년 1월에 진 행되었다. 연구자가 경기도 소재 어린이집 한곳을 선정하여 기관장에게 연구협조 승인을 받은 후 담임교사를 통해 연구목
적과 내용, 절차 및 개인정보 수집 및 활용 등이 작성된 모집문 건과 연구참여 동의서를 학부모에게 배부하고 회수하여, 학부 모가 연구에 참여하기를 희망한 아동에 한해 연구를 진행하였 다. 어린이집 내 조용한 공간에서 아동과 $1: 1$ 면담이 이루어졌 다. 다음으로 온라인을 통해 모집한 경우 모집문건을 배부하 고 연구참여에 동의한 어머니와 아동을 대상으로 조사를 실시 하였다. 어머니와 아동이 희망하는 시간과 장소에 만나 연구 목적과 내용, 절차 등에 대해 설명하고 연구참여 동의서를 작 성한 뒤 진행되었으며, 어머니와 아동이 분리된 공간에서 아 동과 $1: 1$ 면담을 진행하였다.

\section{자료분석}

수집된 자료의 통계분석은 SPSS 22.0 프로그램(IBM Co., Armonk, NY)을 사용하였다. 연구대상자의 사회 인구학적 특 성을 알아보기 위해 빈도와 백분율을 산출하였다. 약속이행 및 위반상황에서 약속이행 및 위반 여부에 대한 이해 및 약속 이행자, 위반자, 피해자의 정서적 반응의 이해의 경향을 살펴 보기 위해 빈도분석을 실시하였다. 다음으로 이러한 약속 이 행 및 위반 상황에 대한 이해 및 약속이행자, 위반자, 피해자의 정서적 반응의 경향이 아동의 연령에 따라 차이를 보이는지 살펴보기 위해 교차분석(chi-square 검증)을 실시하였다.

\section{Results}

연구 1 에서는 아동의 약속이행 및 위반에 대한 이해능력과 약 
Table 1

Promise Fulfillment or Violation of Children and Mothers in Task

\begin{tabular}{|c|c|c|c|c|c|c|}
\hline \multirow[b]{2}{*}{ Situation 1} & \multicolumn{2}{|c|}{ C: Room clean (p) } & \multirow{2}{*}{$\begin{array}{c}\chi^{2} \\
(d f)\end{array}$} & \multicolumn{2}{|c|}{ M: Present (q) } & \multirow{2}{*}{$\begin{array}{c}\chi^{2} \\
(d f)\end{array}$} \\
\hline & Fulfillment & Violation & & Fulfillment & Violation & \\
\hline Age 4 & $30(100.0 \%)$ & $0(0.0 \%)$ & \multirow{3}{*}{$\begin{array}{c}3,092 \\
(3)\end{array}$} & $28(93.3 \%)$ & $2(6.7 \%)$ & \multirow{3}{*}{$\begin{array}{c}2.137 \\
(3)\end{array}$} \\
\hline Age 6 & $31(100.0 \%)$ & $0(0.0 \%)$ & & $31(100.0 \%)$ & $0(0.0 \%)$ & \\
\hline Age 7 & $31(100.0 \%)$ & $0(0.0 \%)$ & & $30(96.8 \%)$ & $1(3.2 \%)$ & \\
\hline Situation 2 & Fulfillment & Violation & $\begin{array}{l}\chi^{2} \\
(d f)\end{array}$ & Fulfillment & Violation & $(d f)$ \\
\hline Age 4 & $19(63.3 \%)$ & $11(36.7 \%)$ & & $6(20.0 \%)$ & $24(80.0 \%)$ & \\
\hline Age 5 & $23(76.7 \%)$ & $7(23.3 \%)$ & $13.680^{* *}$ & $3(10.0 \%)$ & 27 ( 90.0\%) & $9.470^{*}$ \\
\hline Age 6 & $28(90.3 \%)$ & $3(9.7 \%)$ & (3) & $1(3.2 \%)$ & $30(96.8 \%)$ & (3) \\
\hline Age 4 & $5(16.7 \%)$ & $25(83.3 \%)$ & \multirow{4}{*}{$\begin{array}{c}5.883 \\
(3)\end{array}$} & $23(76.7 \%)$ & $7(23.3 \%)$ & \multirow{4}{*}{$\begin{array}{c}14.385^{* *} \\
\text { (3) }\end{array}$} \\
\hline Age 5 & $3(10.0 \%)$ & $27(90.0 \%)$ & & $20(66.7 \%)$ & $10(33.3 \%)$ & \\
\hline Age 6 & $2(6.5 \%)$ & $29(93.5 \%)$ & & $15(48.4 \%)$ & $16(51.6 \%)$ & \\
\hline \multirow[t]{2}{*}{ Age 7} & $0(0.0 \%)$ & $31(100.0 \%)$ & & $10(32.3 \%)$ & $21(67.7 \%)$ & \\
\hline & \multicolumn{2}{|c|}{ C: Room not clean (not p) } & \multirow{2}{*}{$\begin{array}{l}\chi^{2} \\
(d f)\end{array}$} & \multicolumn{2}{|c|}{ M: Not present (not q) } & $\chi^{2}$ \\
\hline Situation 4 & Fulfillment & Violation & & Fulfillment & Violation & $(d f)$ \\
\hline Age 4 & $4(13.3 \%)$ & $26(86.7 \%)$ & \multirow{2}{*}{$\begin{array}{l}5.437 \\
(3)\end{array}$} & $5(16.7 \%)$ & $25(83.3 \%)$ & \multirow{2}{*}{$\begin{array}{c}23.464^{* * *} \\
\text { (3) }\end{array}$} \\
\hline Age 5 & $1(3.3 \%)$ & $29(96.7 \%)$ & & $8(26.7 \%)$ & $22(73.3 \%)$ & \\
\hline
\end{tabular}

Note. $N=122$. $\mathrm{C}=$ children, $\mathrm{M}=$ mother; Right answers were shaded.

${ }^{*} p<.05 .{ }^{* *} p<.01 .{ }^{* * *} p<.001$.

속이행 및 위반으로 인한 정서적 반응에 대한 이해능력이 연 령에 따른 차이가 있는지 살펴보고자 하였다. 먼저 각 상황별, 연령별 주인공 아동과 어머니의 약속이행과 위반 여부에 대해 각각 응답한 결과를 전체적으로 제시하면 Table 1 과 같다. 먼 저 약속상황 1 에서 만 4-7세 아동 대부분은 주인공 아동과 어 머니가 약속을 이행하였다고 응답하여 약속이행을 바르게 이 해한 것으로 볼 수 있다. 약속상황 2에서 주인공 아동이 약속 을 위반하였다고 오답을 이야기한 비율은 만 4 세가 가장 높았 고, 연령이 증가할수록 약속을 이행했다는 정답을 이야기한 비율이 높았으며 이는 통계적으로 유의한 차이를 보였다 $\left(\chi^{2}=\right.$ $13.680, p<.01)$. 어머니의 경우 약속을 위반했다는 응답이 만 4 세가 가장 적었고, 만 6,7 세 대부분의 아동이 약속을 위반하 였다고 응답하였으며 이는 통계적으로 유의한 차이를 보였다 $\left(\chi^{2}=9.470, p<.05\right)$. 약속상황 3에서 만 4-7세 아동 대부분이
주인공 아동이 약속을 위반하였다고 응답하여 약속위반을 바 르게 이해하는 경향을 보였으며, 이는 통계적으로 유의한 차 이를 보이지 않았다. 어머니의 경우, 어머니가 약속을 이행했 다고 응답하여 오답을 이야기한 비율은 만 4-5세가 높았고, 어 머니가 약속을 위반하였다고 정답을 이야기한 응답의 비율은 만 7세가 가장 높았으며 이는 통계적으로 유의한 차이를 보였 다 $\left(\chi^{2}=14.385, p<.001\right)$. 약속상황 4 에서 만 4-7세 아동 대부 분이 주인공 아동이 약속을 위반하였다고 응답하여 약속위반 을 바르게 이해하는 경향을 보였으며, 이는 통계적으로 유의 한 차이를 보이지 않았다. 어머니의 경우 약속을 위반했다는 응답하여 오답을 이야기한 비율이 만 4세 5세에서 높았고, 연령이 증가할수록 어머니가 약속을 이행했다고 정답을 이야 기한 응답의 비율이 높았으며 이는 통계적으로 유의한 차이를 보였다 $\left(\chi^{2}=23.464, p<.001\right)$. 
Table 2

Children's and Mothers' Emotional Responses to Promise Fulfillment or Violation in Task

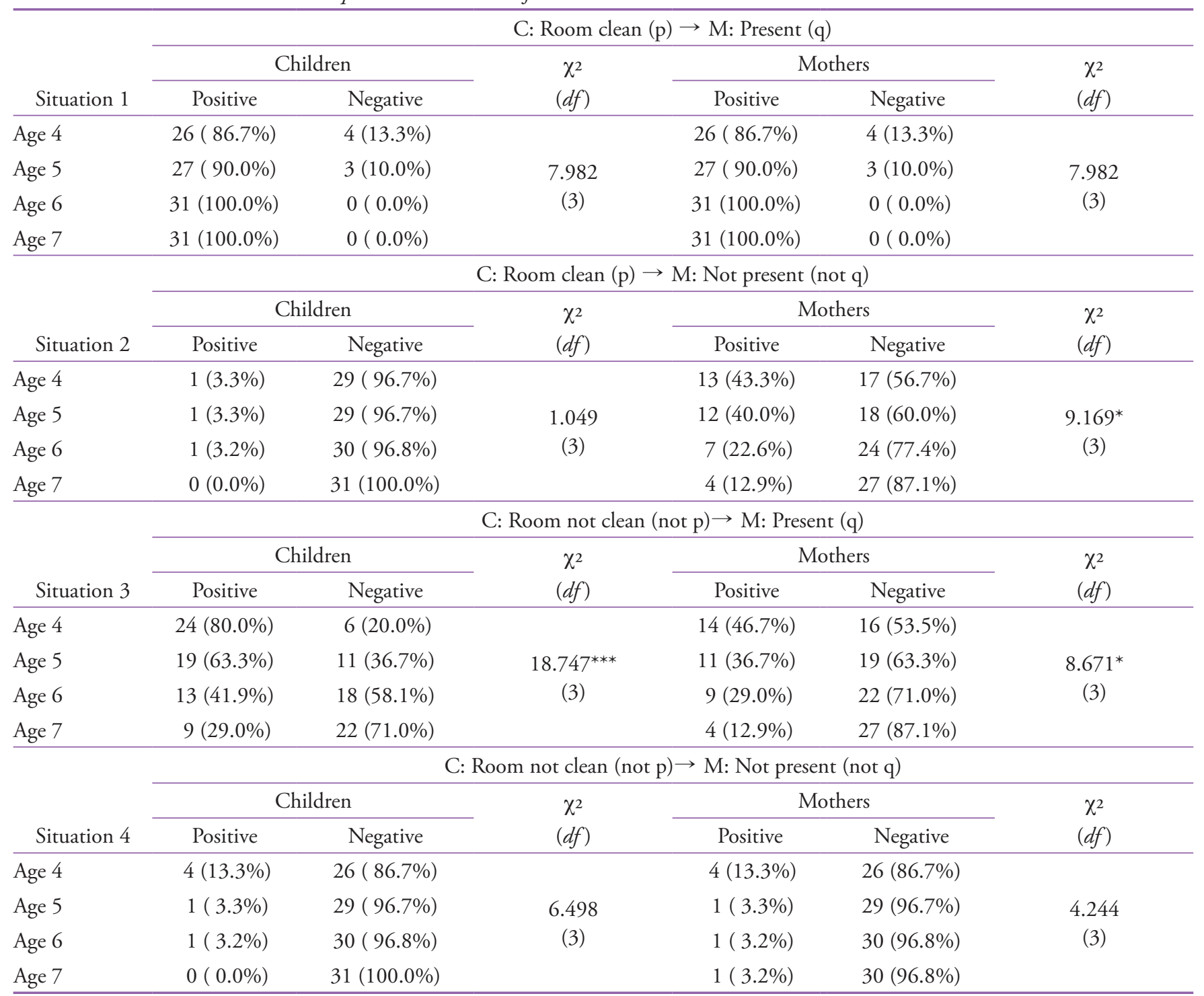

Note. $N=122$.

${ }^{*} p<.05 .{ }^{* * *} p<.001$.

다음으로 약속이행 및 위반상황에서 약속이행자, 위반자, 피해자가 어떤 정서적 반응을 보였을 것인지에 대해 아동이 어떠한 양상으로 응답하였는지 살펴보기 위하여 4가지 약속 이행 및 위반상황에 대해 아동이 응답한 분포를 Table 2 에 제 시하였다. 먼저 약속상황 1에서 만 4-7세 아동 대부분 주인공 아동과 어머니가 긍정 정서를 느낀다고 응답하는 경향을 보였 으며, 연령에 따른 유의미한 통계적 차이는 나타나지 않았다. 약속상황 2에서 만 4-7세 아동 대부분 주인공 아동은 부정정 서를 느낄 것이라고 응답하였으며, 연령에 따른 유의미한 통 계적 차이는 나타나지 않았다. 반면 만 6,7 세가 만 4,5 세에 비
하여 어머니가 부정정서를 느낄 것이라는 응답이 높은 경향을 보였으며, 이는 통계적으로 유의한 차이가 있었다 $\left(\chi^{2}=9.169\right.$, $p<.05)$. 약속상황 3 에서 주인공 아동이 긍정정서를 느낀다고 응답의 비율은 만 4세가 높은 반면, 부정정서를 느낀다는 응답 의 비율은 연령이 증가할수록 높았으며, 이는 통계적으로 유 의한 차이를 보였다 $\left(\chi^{2}=18.747, p<.001\right)$. 어머니의 경우 만 6 , 7 세가 만 4,5 세에 비하여 어머니가 부정정서를 느낀다는 응 답이 높은 경향을 보였으며, 이는 통계적으로 유의한 차이가 있었다 $\left(\chi^{2}=8.671, p<.05\right)$. 약속상황 4에서 만 4-7세 아동 대 부분이 주인공 아동과 어머니가 부정정서를 느낀다고 응답하 
였으며, 통계적으로 유의한 차이는 없었다.

\section{Study 2}

연구 1 의 결과 아동의 연령이 증가할수록 약속이행과 위반 및 약속이행과 위반으로 인한 정서적 반응에 대해 이해하는 능력 이 증가하여 발달적 차이가 있음을 확인하였다. 그러나 아동 이 인식하는 것과 실제 경험에서 차이가 있다는 Smith, Blake 와 Harris (2013)의 연구를 고려할 때 아동이 약속이행과 위반 을 이해하는 능력보다는 일상에서 어머니가 약속을 이행하고 위반하는 경험이 자녀의 발달에 직접적인 영향을 미칠 것으 로 예측되어, 연구 2에서는 조건 약속이행과 위반에 대한 이 해능력을 바탕으로 실제 어머니와의 조건 약속이행 및 위반경 험이 아동에게 어떠한 효과가 있는지에 대해 살펴보고자 하였 다. 약속이행과 위반은 신뢰와 밀접한 관련이 있는 행위로 간 주된다. Rotenberg 등(2005)은 대인관계에 대한 신뢰를 인지 적 신뢰, 정서적 신뢰를 포함한 다차원적 개념을 제시하였으 며, 신뢰는 사람에 대한 신념이자, 사람들의 행동에 대한 긍정 적 기대감으로 설명하였다. 이러한 신뢰는 사회적 상호작용을 통해 발달하며(Uslander, 2013), 특히 상대방이 일관되게 약속 을 이행하는 경험을 통해 형성된다(Rotenberg, 1980). 이러한 점에서 어머니의 약속이행 및 위반경험은 자녀의 어머니에 대 한 신뢰감에 영향을 미칠 것으로 예측해볼 수 있다. 아동의 어 머니에 대한 신뢰감과 직접적인 관계를 살펴본 연구는 매우 드물지만, 약속이행과 위반행동이 신뢰감과 밀접한 관계가 있 다는 선행연구(Schniter, Sheremeta, \& Sznycer, 2013)와 아동이 상대방의 약속이행 여부에 따라 신뢰를 판단한다는 선행연구 (Rotenberg, 1980)를 통해 어머니의 약속이행과 위반행동이 아 동의 어머니에 대한 신뢰감과의 관계를 유추해볼 수 있다. 어 머니에 대한 신뢰가 형성되면, 어머니의 지시나 요구, 통제를 수용하고 내면화할 수 있어 자기조절능력의 기초를 형성하게 된다(Thompson, 2015; Zimmermann \& Iwanski, 2015). 자기조 절능력은 사회적 요구에 맞게 자신의 행동과 정서를 적절히 조절할 수 있는 능력으로(Kopp, 1982). 아동의 적응적 발달을 위해 유아기부터 발달시켜야 하는 주요 과업 중 하나이다. 이 러한 아동의 자기조절능력은 가정에서 주양육자인 어머니와 의 관계 속에서 형성된다(Erikson, 1963; Siegel, 2012). Erikson (1963)에 따르면 주 양육자인 어머니가 자녀에 대해 일관되게 민감하고 반응적으로 대하는 태도를 보임으로써 자녀는 어머 니에 대한 행동을 예측할 수 있고, 어머니를 믿고 신뢰할 수 있
으며, 이러한 어머니에 대한 신뢰감을 바탕으로 자신의 정서 를 조절하고, 욕구와 좌절을 인내하고 기다리는 행동을 습득 할 수 있다고 하였다(Zimmermann \& Iwanski, 2015). 결과적으 로 아동이 어머니의 약속 이행 및 위반 행동을 경험하게 되면 어머니의 행동을 예측하고 기대함으로써 어머니에 대한 신뢰 감을 형성하고, 이러한 신뢰감이 내적기제로 작동하여 아동은 환경에 대해 이해하고 환경의 요구에 맞게 적절히 자신을 조 절해갈 수 있는 능력을 갖게 될 것으로 예측해 볼 수 있다. 연 구 2에서는 실제 일상생활에서 아동이 겪은 어머니의 약속이 행 및 위반경험이 어머니에 대해 갖는 신뢰감과 자기조절능력 의 발달에 어떠한 영향을 미치는지를 살펴보고자 하였다.

\section{연구문제 1}

아동이 지각하는 어머니의 약속이행 및 위반 경험이 어머니 에 대한 신뢰감을 통해 자기조절능력에 간접적 영향을 미치 는가?

\section{Methods}

\section{연구대상}

연구 2 에서는 연구 1 에 참여하였던 만 4세와 만 5 세 각각 30 명, 만 6세와 만 7세 각각 31명 총 122명(남아 60명, 여아 62명) 그들의 어머니를 연구대상으로 하였다. 아동의 어머니 연령은 평균 37.1 세이다.

\section{연구도구}

약속이행 및 위반에 대한 경험

어머니의 약속이행 및 위반 경험을 파악하기 위해 기존의 어머니와의 약속경험에 대해 연구한 Choi (2000)의 연구와 Rotenberg (2005)의 척도의 문항 내용을 참고하여 3가지 상황 의 내용을 구성하였다. 3 가지의 약속상황은 '숙제를 하면 TV 또는 핸드폰을 더 보여주겠다는 약속' '밥을 잘 먹으면 핸드폰 을 더 할 수 있다는 약속', '공공장소에서 얌전히 있으면 장난 감을 사주겠다는 약속'이다. 각 상황마다 아동의 약속이행시 어머니가 약속을 이행 또는 위반하였는지, 아동의 약속위반시 어머니가 약속을 이행 또는 위반하였는지를 질문하여, 총 6 문 항으로 구성하였다. 어머니가 약속을 이행한 경우에는 1점, 약 
속을 위반한 경우에는 0 점으로 총 6 문항을 합산하여 분석하였 고, 점수가 높을수록 어머니가 일관되게 약속을 이행함을 의미 한다. 본 측정도구의 신뢰도(Cronbach's $\alpha$ ) 계수는 .52이다.

\section{어머니에 대한 신뢰감}

아동의 어머니에 대한 신뢰감을 측정하기 위해 Rotenberg 등 (2005)이 개발, 타당화한 아동의 대인관계 신뢰신념 척도 (Children's Generalized Trust Beliefs [CGTB])를 수정하여 사용 하였다. 이 도구는 엄마, 아빠, 교사, 또래 4 명의 대상에 대하여 3 가지 측면의 신뢰(믿음, 정서적 신뢰, 정직)를 측정하기 위한 각 하위요인별 2 개의 에피소드로 구성되어 있다. 본 연구에서 는 조사대상 아동과 자신의 어머니에 대한 에피소드로 수정하 여 사용하였다. 각 문항에 대해 매우 그렇지 않을 것이다(1점) 에서 매우 그럴 것 같다(4점)로 응답하도록 한다. 본 연구에서 측정도구의 신뢰도(Cronbach's $\alpha$ ) 계수는 .69로 나타났다.

\section{자기조절능력}

자기조절능력을 측정하기 위해 Olson과 Kashiwagi (2000)의 연 구에서 교사 보고용으로 개발된 행동적 자기조절(behavioral self-regulation) 척도를 Moon (2007)이 번안, 수정한 질문지를 어머니 보고용으로 수정하여 사용하였다. 문항의 예는 “잠깐 만 기다려 라고 지시할 때 기다릴 수 있다.”, “방해하지 않고 다른 사람의 이야기를 들을 수 있다.” 등이 있다. 각 문항에 대 해 전혀 그렇지 않다(1점)에서 매우 그렇다(5점)로 응답하며, 점수가 높을수록 자기조절능력이 높음을 의미한다. 측정도구 의 신뢰도(Cronbach's $\alpha$ ) 계수는 .90으로 나타났다.

\section{통제변수}

연구 2에서의 주된 목적은 어머니의 약속 이행 및 위반 경험이 아동의 어머니에 대한 신뢰감을 통해 자기조절능력에 미치는 영향을 규명하는 것이므로 아동의 연령이 미치는 영향을 최소 화하기 위하여 연령을 통제하여 분석하였다.

\section{연구절차}

연구대상 표집이 어린이집을 통해 이루어진 경우, 연구목적과 내용, 절차 등이 작성된 모집문건을 읽고 연구에 참여하기를 희망한 어머니가 연구참여 동의서와 질문지를 작성한 어머니
에 한해 자료를 수집하였으며, 아동과 면담을 하는 날 어머니 의 질문지를 회수하였다. 온라인을 통해 모집한 경우, 연구자 는 어머니와 아동이 희망하는 장소에 만나 연구자가 어머니와 분리된 공간에서 아동과 면담을 실시하는 동안, 어머니는 질문 지를 작성하고 아동의 면담을 마친 후 질문지를 회수하였다.

\section{자료분석}

본 연구에서는 수집된 자료를 분석하기 위하여 SPSS 21.0 (IBM Co., Armonk, NY)을 사용하였다. 측정도구의 신뢰도를 파악하기 위해 Cronbach's $\alpha$ 계수를 산출하였다. 연구변인들 간의 상관관계를 살펴보기 위해 연령을 통제하여 부분상관분 석을 실시하였다. 마지막으로 연구문제 분석을 위해 아동과 어머니가 지각한 어머니의 약속 이행 및 위반 경험이 아동의 어머니에 대한 신뢰감과 아동의 자기조절능력에 미치는 간접 효과를 검증하기 위해 선형회귀분석(linear regression analysis) 을 실시하였으며, Sobel test를 사용하여 간접효과의 통계적 유 의성을 검증하였다.

\section{Results}

아동이 지각한 약속이행 및 위반경험, 어머니에 대한 신뢰감, 자기조절능력 간 관계를 살펴보기 위해 연령을 통제하여 부 분상관 분석을 실시하였다. 먼저 아동이 지각한 약속경험과 어머니에 대한 신뢰감은 유의한 정적상관을 보여 $(r=.31 p<$ $.01)$, 어머니가 약속을 일관되게 이행한다고 아동이 지각할수 록 어머니에 대한 신뢰감이 높은 것으로 나타났다. 또한 어머 니에 대한 신뢰감과 아동의 자기조절능력 간의 유의한 정적 상관을 보여 $(r=.40, p<.001)$, 어머니에 대한 신뢰감이 높을수 록 자기조절능력이 높은 것으로 나타났다.

다음으로 아동이 지각한 어머니의 약속 이행 및 위반 경험 이 아동의 어머니에 대한 신뢰감에 어떠한 영향을 미치는지 살펴보기 위해 아동의 연령을 통제하여 회귀분석을 실시하였 다. 그 결과 아동이 지각한 어머니의 약속 이행 및 위반 경험 은 어머니에 대한 신뢰감에 유의한 정적 영향을 미치는 것으 로 나타나 $(\beta=.32 p<.01)$, 어머니가 약속을 일관되게 이행한 다고 아동이 지각하는 것은 어머니에 대한 신뢰감에 긍정적인 영향을 미치는 것으로 볼 수 있다.

다음으로 어머니에 대한 신뢰감이 아동의 자기조절능력 에 영향을 미치는지 살펴보기 위해 연령을 통제하여 회귀분석 


\section{Children's Conditional Promise and Trust with Mothers}

Table 3

Descriptive Statistic Analysis and Partial Correlations among Variables

\begin{tabular}{|c|c|c|c|}
\hline Variables & 1 & 2 & 3 \\
\hline 2. Children's trust in mothers & $.31^{* *}$ & - & \\
\hline 3. Self-regulation & .12 & $.40^{* * *}$ & - \\
\hline$M$ & 4.83 & 3.13 & 3.74 \\
\hline Skewness & -.55 & -.68 & -.37 \\
\hline Kurtosis & -.83 & -.19 & .26 \\
\hline
\end{tabular}

Note. $N=122$.

${ }^{* *} p<.01{ }^{* * *} p<.001$.

Table 4

The Effect of Children's Experience of Motehrs' Promise Fulfillment and Violation on Children's Trust in Mothers

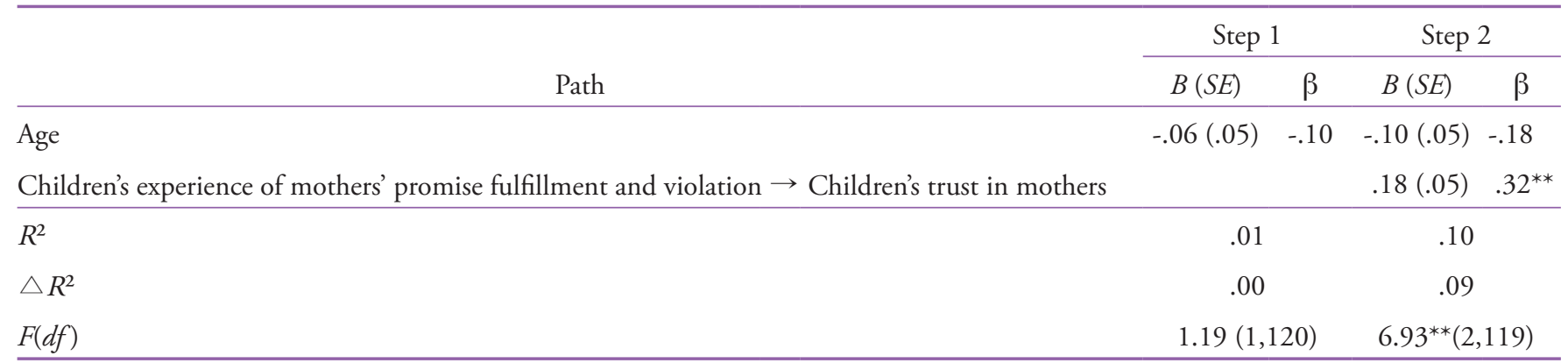

Note. $N=122$.

${ }^{* *} p<.01$.

Table 5

The Effect of Children's Trust in Mothers on Self-Regulation

\begin{tabular}{|c|c|c|c|c|}
\hline Path & \multicolumn{2}{|c|}{ Step 1} & \multicolumn{2}{|c|}{ Step 2} \\
\hline Age & $.05(.03)$ & .16 & $.07(.03)$ & $.20^{*}$ \\
\hline Children's trust in mothers $\rightarrow$ Self-regulation & & & $.24(.05)$ & $.40^{* * *}$ \\
\hline$R^{2}$ & \multicolumn{2}{|c|}{.03} & \multicolumn{2}{|c|}{.18} \\
\hline$F(d f)$ & \multicolumn{2}{|c|}{$3.07(1,120)$} & \multicolumn{2}{|c|}{$13.46^{* * *}(2,119)$} \\
\hline
\end{tabular}

Note. $N=122$.

${ }^{*} p<.05 .{ }^{* * *} p<.001$.

을 실시하였다. 그 결과 아동의 어머니에 대한 신뢰감은 자기 조절능력에 유의한 정적 영향을 미치는 것으로 나타났다 $(\beta=$ $.40, p<.001)$. 즉, 아동의 어머니에 대한 높은 신뢰감은 자기조 절능력에 긍정적인 영향을 미치는 것으로 볼 수 있다.

본 연구에서 어머니에 대한 신뢰감의 간접효과의 유의성을
통계적으로 검증하기 위해 Sobel-test를 실시한 결과, $Z=2.88$ 로 유의수준 .01에서 간접효과가 유의한 것으로 나타났다. 즉, 어머니의 약속 이행 및 위반 경험은 어머니에 대한 신뢰감을 통해 아동의 자기조절능력에 간적접인 영향을 미치는 것으로 나타났다. 


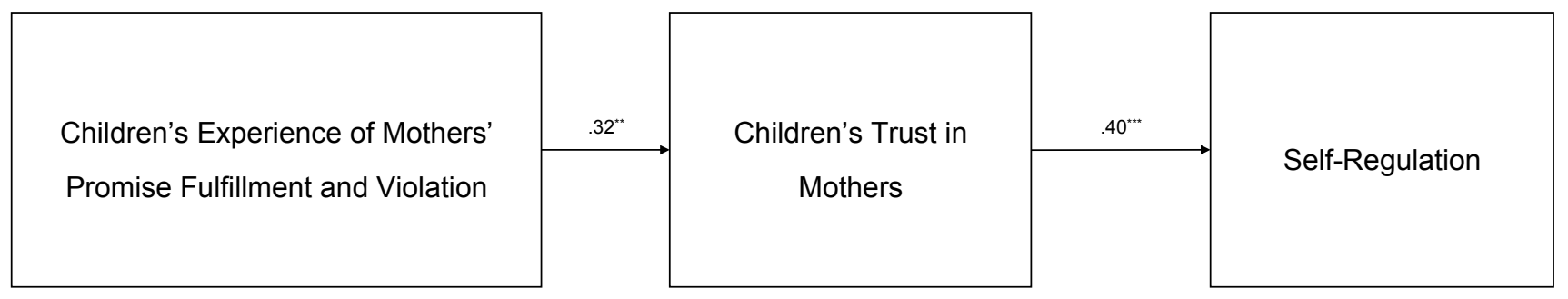

Figure 2. The effect of children's experience of mothers' promise fulfillment and violation on self-regulation through children's trust in mothers.

${ }^{* *} p<.01 .{ }^{* * *} p<.001$.

\section{Discussion}

본 연구 1 에서는 조건 약속이행과 위반에 대한 아동의 이해와 약속이행과 위반으로 인한 정서적 반응에 대한 아동의 이해를 살펴보았다. 그 결과 약속이행과 위반을 이해하고 약속이행 과 위반으로 인한 정서적 반응을 이해하는 능력은 만 4세에도 형성되나, 약속이행과 위반의 상황(일방적 위반 혹은 상호 위 반)에 따라 연령에 따라 이해능력에 발달적 차이가 있는 것으 로 나타났다. 연령이 증가할수록 조건 약속이행과 위반에 대 한 이해가 높았으며, 아동은 어머니보다 주인공 아동의 약속 위반에 대해 보다 정확한 이해를 하는 것으로 나타나, 아동은 자신과 유사한 연령의 아동에게 쉽게 공감되고 자신의 상황으 로 연결하여 이해한다는 점을 시사한다. 또한, 약속이행과 위 반으로 인한 정서적 반응의 경우 약속을 위반한 주체에 따라 차이를 보였다. 주인공 아동이 약속을 위반하더라도 어머니로 부터 긍정적인 보상이 주어졌을 때에는 위반자인 주인공 아동 이 긍정적 정서를 느낄 것이라는 응답이 상대적으로 높았다. 이는 행복한 위반자 현상(happy victimizer)으로 해석될 수 있으 며, 어머니가 선물을 제공하는 행위를 약속위반으로 인식하기 보다는 긍정적 양육의 한 측면으로 이해했을 가능성이 있다.

나아가 본 연구 2에서는 약속을 이행하는 행동은 도덕적 행 동의 한 측면이라 할 수 있으며, 상호 신뢰의 기초가 된다는 점 을 고려하여 아동의 발달에 미치는 유의미한 영향이 있을 것으 로 예측하였다. 또한 유아기는 자기조절능력의 기초가 마련되 는 중요한 발달적시기로 자기조절능력에 어머니의 변인이 중 요한 역할을 할 것으로 예측하였다. 이에 어머니의 약속이행과 위반의 경험이 아동의 어머니에 대한 신뢰감을 통해 아동의 자 기조절능력에 어떠한 영향을 미치는지 규명하고자 하였다. 연 구 2에서는 실제 어머니와 자녀와의 약속상황에서 어머니의 약 속이행과 위반의 경험이 어머니에 대한 신뢰감을 통해 아동의 자기조절능력에 미치는 영향력을 살펴보았다. 그 결과 어머니
가 일관된 약속을 이행하는 것은 아동의 신뢰감을 높이며, 아동 의 높은 신뢰감이 자기조절능력을 높이는 것으로 나타났다.

연구 1 과 연구 2 의 결과를 중심으로 종합적인 논의를 하면 다음과 같다. 본 연구결과 아동이 일상생활에서 자녀가 어머 니가 조건약속상황에서 약속을 이행하고 위반하는 경험이 아 동의 발달에 영향을 미치는 중요한 변인임을 확인하였다 그러 나 조건약속의 이행과 위반을 이해하는데 인지적 능력이 주 요한 전제이며, 이해하는 능력에 발달적 차이가 있음을 고려 할 때, 일상생활에서 어머니가 약속을 위반하게 되었을 때 혹 은 자녀가 약속을 위반하게 되었을 때에 약속 위반에 대한 자 녀의 인지적 이해를 돕기 위해 언어적으로 설명해주고 지도하 는 것이 중요하다고 볼 수 있다. 유아교육 현장에서도 어린 아 동에게 '약속 지키기’를 지도할 때 약속을 경험하고 이해할 수 있도록 지도하는 것이 중요하며, 이를 위해 약속을 지켜야 하 는 이유와 약속을 지키지 않을 때 발생하는 결과에 대해 설명 하는 방식을 사용하고 있으며 유아에게 모범적 행동을 보임으 로써 보고 배울 수 있도록 지도해야함을 강조하고 있으며 $(\mathrm{Ha}$, 2013), Son (2017)의 연구에서도 아이들이 약속을 '지키지 않 으면 안 되는 것이며 약속을 지키지 않을 때 처벌이 따르는 것' 으로 인식하는데 있어 교사의 행동과 지도가 영향을 미쳤다고 설명하였다. 따라서 가정에서도 어머니가 평소 약속을 이행하 는 모범적 행동을 보이고 자녀와 대화하고 지도함으로써 자녀 가 약속이행의 중요성을 이해하고 약속이행과 위반을 이해할 수 있도록 경험을 제공하는 것이 중요하다.

다음으로, 기존의 많은 연구들에서는 아동의 자기조절능력 발달에 영향을 미치는 요인으로 어머니의 양육변인에 초점을 두고 있다. 어머니가 자녀에게 애정적이고 반응적으로 대하며 규칙과 생활규범 등에 대해 가르치며, 합리적으로 설명하고 지 도하는 행동이 자녀의 자기조절능력의 발달에 유의한 영향을 미친다고 보고되어 왔다(Lee, 2010). 본 연구에서는 어머니의 양육행동 중에서도 어머니가 일상생활에서 자녀와의 약속을 
이행하는 모습이 자녀에게 사회적 관계에서 약속을 준수하는 도덕적 행동의 모델링의 역할을 함과 동시에 어머니의 행동에 대한 예측하고 기대할 수 있는 내적표상을 형상하도록 하며, 어머니에 대한 신뢰감이라는 내적기제가 작동하여 아동은 환 경을 이해하고 환경의 요구에 맞게 자신을 조절할 수 있는 능 력을 갖도록 함으로써 결과적으로 아동의 자기조절능력을 발 달하는데 중요한 역할을 한다는 점을 규명하였다. 따라서 어머 니가 일관되게 약속을 이행하는 행동을 통해 아동은 어머니의 행동을 예측하고 신뢰할 수 있고, 이러한 어머니에 대한 믿음 과 신뢰를 바탕으로 타인과 환경에 대한 신념을 형성함으로써, 원만한 사회적 관계를 형성하고, 사회적 적응에 요구되는 자신 을 조절할 수 있는 능력을 발달시킬 수 있을 것이다.

본 연구는 몇 가지 한계점과 후속연구에 대한 제언은 다음 과 같다. 첫째, 본 연구에서는 아동의 자기조절능력을 어머니 의 보고만으로 측정하여 어머니의 주관과 선입견, 사회적 바 람직성의 영향이 있을 수 있다. 후속연구에서는 보다 객관적 측정을 위해서 교사의 보고를 함께 진행하는 것을 고려할 필 요가 있다. 둘째, 실제 어머니-자녀 간에 이루어지는 조건약속 상황에서 어머니의 약속이행과 위반행동을 측정하는 도구의 아동이 응답한 경우의 신뢰도가 .52로 낮은 점수였으나, 신뢰 도 계수가 .5 .75는 일반적으로 수용할 수 있다는 선행연구 (Hinton, McMurray, \& Brownlow, 2014)를 근거로 본 연구에서 도 수용할 만한 점수로 판단하였다. 셋째, 조건약속은 약속의 개념에 대한 이해와 조건문 형식을 이해하고 있는지에 대한 이해를 전제로 한다. 그러나 본 연구에서 약속이행과 위반 이 해 과제에서 조건약속을 제시하기 이전에 약속의 개념과 조건 문에 대한 이해하고 있는지 충분한 점검이 부족한 편이었다. 앞으로의 연구에서는 기초적인 약속의 개념과 조건문을 이해 하고 있는지를 점검하는 과정을 추가함으로써 아동이 조건약 속의 이해의 기초가 되는 인지적 능력을 확인하는 연구 설계 로 보완될 필요가 있다.

이러한 한계점에도 불구하고 본 연구는 아동발달 연구에서 크게 주목받지 못했던 어머니와 자녀와의 관계에서 이루어지 는 약속이행 및 위반에 대해 살펴봄으로써 학문적 의의를 갖는 다. 연구 1 에서는 조건약속 상황에서 약속이행과 위반에 대한 이해와 약속이행과 위반으로 인한 정서적 반응에서 연령에 따 른 발달적 차이를 확인하였다. 조건약속은 상호 약속을 이행할 의무를 포함하고 있으며 약속이행과 위반을 이해하기 위해서 는 조건문을 이해할 수 있는 인지적인 능력이 요구된다. 본 연 구에서는 아동의 약속 이행과 위반을 이해하는 능력을 살펴보 기 위해 약속 이행과 위반을 판단하는 인지적인 이해능력과 함
께 정서적 반응을 이해하는 능력을 이해의 범주에 포함하여 살 펴보았다. 아동의 정서적 반응에 대한 이해능력을 약속이행과 위반을 이해하는 능력의 큰 범주 안에 포함시켜 살펴보았는데, 이는 어린 연령의 아동이 모든 약속이행과 위반상황을 정확하 게 판단하는 데 어려움을 보인다 하더라도, 약속이행과 위반상 황에서 경험 될 수 있는 정서적 반응에 대해 어느 정도 이해할 수 있는 능력을 갖추고 있다면 이는 약속위반 여부를 인지적으 로 이해하는 능력의 기초가 될 수 있을 것으로 판단하였기 때 문이다. 본 연구의 결과로 어린 연령의 유아는 약속이행과 위 반여부와 약속이행과 위반상황에서 약속 당사자들이 경험하 는 정서적 반응을 정확하게 이해하지 못하더라도, 어떤 상황에 서 다른 사람의 입장이 되어보고, 자신이 느끼는 것과는 다르 게 다른 사람이 느끼는 정서를 이해하고 추론하고자 하는 능 력의 발달은 인지적으로 상황을 판단하는 능력의 발달과 함께 중요하다는 점을 시사하며, 이를 바탕으로 추후 연구에서는 약 속이행 및 위반이해와 정서적 반응이해에 대한 보다 더 통합적 인 접근을 통하여 심도있게 접근할 필요성이 제기된다. 이러한 통합적인 접근을 발전시켜 약속이행과 위반에 대한 연구에서 도출할 결과를 바탕으로 부모교육과 교육기관에 활용할 수 있 는 실제적 정보를 제공할 수 있을 것이다.

뿐만 아니라 선행연구에서는 조건약속 중 'not p, q'를 p의 일방적 상호위반, 'not p, not q'를 p와 q의 상호 약속 위반으로 해석하였다(Barrett, et al., 2007; Chin \& Lin, 2018; Keller et al., 2004). 그러나 본 연구에서는 조건약속의 형태(if , then)를 고 려할 때, 'p, q'에 대해 $\mathrm{p}$ 가 약속을 이행하는 것이 선행되고, $\mathrm{p}$ 의 약속이행의 결과로 $\mathrm{q}$ 도 약속된 행동을 하는 것이 논리적인 규 칙으로 판단하였다. 따라서 not $\mathrm{p}, \mathrm{q}$ 에 대해 $\mathrm{p}$ 와 $\mathrm{q}$ 의 상호 약속 위반, not $\mathrm{p}$, not $\mathrm{q}$ 에 대해 $\mathrm{p}$ 의 일방적 약속위반 즉, $\mathrm{p}$ 가 약속을 위반한 결과로 $\mathrm{q}$ 의 행동은 약속 이행으로 사용함으로써 논리 적 규칙을 반영한 조건약속의 이행과 위반의 개념을 재조명하 였다는 점에서 의의가 있다. 또한, 약속에 대해서도 단편적으 로 약속을 지켰는지, 지키지 않았는지와 같은 약속이행 및 위 반 여부만을 판단한 것이 아니라, 조건부 일 때 선행된 약속의 이행 및 위반여부에 따라, 이후의 약속의 이행 및 위반 여부를 판단하고, 주인공 아동과 어머니를 각각 구분하여 약속이행 및 위반 여부를 판단함으로써 약속 당사자의 관점에 따라 이 해능력을 살펴보았다. 더불어 약속이행과 위반의 결과로 인해 약속 이행자, 위반자, 피해자의 관점에서 경험하는 정서적 반 응에 대한 이해능력에 대해 다각도에서 살펴봄으로써 아동의 이해능력에 대한 이해의 폭을 넓혔다는 점에서 의의가 있다.

또한 본 연구에서는 발달적 관점에서 어머니의 약속이행 
과 위반의 경험이 어머니에 대한 신뢰감을 통해 자기조절능력 에 미치는 영향력을 살펴봄으로써 기존의 아동의 약속이행과 위반 이해능력에 대한 연구와 어머니의 행동이 자녀의 발달 에 미치는 과정에 대해 깊이 있는 설명을 가능하도록 하였다 는 점에서 연구의 의의가 있다. 지금까지 국내외에서 어머니 의 양육행동 중에서 어머니와 자녀와의 약속을 이행하고 위반 하는 행동이 자녀의 발달에 어떠한 미칠 수 있는 지 발달적 접 근의 선행연구는 찾아보기 어려웠다. 그러나 연구 2에서는 실 제 어머니와 자녀 간의 관계에서 이루어지는 조건 약속상황에 서 어머니의 약속이행과 위반행동이 자녀가 어머니를 믿고 신 뢰할 수 있는 토대가 될 뿐만 아니라 어머니에 대한 신뢰감을 통해 자녀의 자기조절능력에 간접적인 영향을 미칠 수 있음을 확인하였다. 그동안 신뢰는 주로 경제학, 경영학, 사회학 분야 에서 연구되어왔으며, 발달심리학적 관점에서는 주로 정서적 유대감에 기초한 어머니에 대한 신뢰감을 살펴봄으로써 어머 니의 약속이행과 위반행동에 대한 지각이 아동의 어머니에 대 한 신뢰감을 통해 자기조절능력에 영향을 미치는 과정을 살펴 볼 수 있는 이론적 배경이 부족하였다. 또한 어머니에 대한 신 뢰감을 정서적 유대감에 기초하여 살펴본 선행 연구들에서도 아동이 직접 응답한 경우는 드물었다. 그러나 연구 2에서는 어 머니에 대한 정서적 유대감에 기초한 신뢰 뿐 만 아니라 어머 니의 행동을 토대로 형성된 어머니의 행동에 대한 기대감, 예 측가능성의 의미를 포함한 인지적 측면의 신뢰를 동시에 고려 함으로써 인지와 정서 요소가 함께 작용하여 형성된 신뢰감이 자녀의 자기조절능력에 유의한 영향을 미친다는 점을 밝혔다. 이러한 점에서 본 연구의 결과는 유아와 아동의 교육 현장에 있는 교사들과 어린 연령의 자녀를 둔 어머니, 그리고 이들을 대상으로 한 부모교육 프로그램 개발자에게 시사점을 제공하 고 있으며, 유아와 아동을 지도하는 교육기관에서 유용한 자 료로 활용될 수 있을 것이며, 부모교육 프로그램의 자료로 활 용될 수 있을 것으로 기대한다.

\section{Notes}

This article is a part of the first author's doctoral dissertation submitted in 2020, and was presented at the 2020 Annual Fall Online Conference of the Korean Association of Child Studies.

\section{Conflict of Interest}

No potential conflict of interest relevant to this article was reported.

\section{Ethics Statement}

All procedures of this research were reviewed by IRB (ewha201909-0017-01).

\section{References}

\section{In English}

Astington, J. W. (1988). Promises: Words or deeds? First Language, 8(24), 259-270. doi:10.1177/014272378800802404

Barrett, H. C., Keller, M., Takezawa, M., \& Wichary, S. (2007). Relationships and emotions in children's understanding of social contract violations. Journal of Evolutionary Psychology, 5(1), 213-234. doi:10.1556/jep.2007.1022

Chin, J. C., \& Lin, M. H. (2018). Children's understanding of conditional promise contract violations. Infant and Child Development, 27(3), 1-17. doi:10.1002/icd.2082

Dias, M. G., \& Harris, P. L. (1990). The influence of the imagination on reasoning by young children. British Journal of Developmental Psychology, 8(4), 305-318. doi:10.1111/ j.2044-835x.1990.tb00847.x

Erikson, E. H. (1963). Childhood and society. New York: W. W. Norton \& Company.

Hawkins, J., Pea, R. D., Glick, J., \& Scribner, S. (1984). "Merds that laugh don't like mushrooms": Evidence for deductive reasoning by preschoolers. Developmental Psychology, 20(4), 584-594. doi:10.1037/0012-1649.20.4.584

Hinton, P. R., Mc Murray, I., \& Brownlow, C. (2014). SPSS explained (2nd ed.). London: Routledge.

Keller, M., Gummerum, M., Tien Wang, X., \& Lindsey, S. (2004). Understanding perspectives and emotions in contract violation: Development of deontic and moral reasoning. Child Development, 75(2), 614-635. doi:10.1111/j.14678624.2004.00696.x

Kopp, C. B. (1982). Antecedents of self-regulation: A developmental perspective. Developmental psychology, 18(2), 199-214. doi:10.1037/0012-1649.18.2.199

Nakamichi, K. (2004). Young children's conditional reasoning on the four-cards selection task: The influence of context and experience. Psychologia, 47(4), 238-249. doi:10.2117/ 
psysoc.2004.238

Nunner-Winkler, G., \& Sodian, B. (1988). Children's understanding of moral emotions. Child Development, 59(5), 1323-1338. doi:10.2307/1130495

Olson, S. L., \& Kashiwagi, K. (2000). Teacher ratings of behavioral self-regulation in preschool children: A Japanese/US comparison. Journal of Applied Developmental Psychology, 21(6), 609-617. doi:10.1016/S0193-3973(00)00056-3

Rotenberg, K. J. (1980). "A promise kept, a promise broken": Developmental bases of trust. Child Development, 51(2), 614617. doi:10.2307/1129307

Rotenberg, K. J., Fox, C., Green, S., Ruderman, L., Slater, K., Stevens, K., \& Carlo, G. (2005). Construction and validation of a children's interpersonal trust belief scale. British Journal of Developmental Psychology, 23(2), 271-293. doi:10.1348/026151005X26192

Searle, J. R. (1969). Speech acts: An essay in the philosophy of language. New York: Cambridge University Press.

Siegel, D. J. (2012). The developing mind: How relationships and the brain interact to shape who we are (2nd ed.). New York: The Guilford Press.

Schniter, E., Sheremeta, R. M., \& Sznycer, D. (2013). Building and rebuilding trust with promises and apologies. Journal of Economic Behavior \& Organization, 94, 242-256. doi:10.2139/ ssrn. 2144021

Smith, C. E., Blake, P. R., \& Harris, P. L. (2013). I should but I won't: Why young children endorse norms of fair sharing but do not follow them. PloS ONE, 8(3), 1-11. doi:10.1371/ journal.pone.0059510

Thompson, R. A. (2015). Relationships, regulation, and early development. In R. M. Lerner (Series Ed.) \& M. Lamb (Vol. Ed.), Handbook of child psychology and developmental science: Socioemotional Processes (7th ed., Vol. 3, pp. 201-246.). New York: John Wiley \& Sons Inc.

Trabasso, T., Stein, N. L., \& Johnson, L. R. (1981). Children's knowledge of events: A causal analysis of story structure. In G. H. Bower (Ed.), Psychology of learning and motivation (Vol. 15, pp. 237-282). Cambridge, MA: Academic Press.

Uslaner, E. M. (2013). Trust as an alternative to risk. Public Choice, 157, 629-639. doi:10.1007/s11127-013-0082-x

Zimmermann, P., \& Iwanski, A. (2015). Attachment in middle childhood: Associations with information processing. New Directions for Child and Adolescent Development, 2015(148), 47-61. doi:10.1002/cad.20099

\section{In Korean}

Choi, Y. (2002) The development of children's understanding of promise and changes in promise-keeping behaviors during the elementary school years (Master's thesis). Retrieved from http://www.riss.kr/link?id=T8955330
Ha, M. K. (2013). An ethnographic study on the 'promise' of 3-yearsold children (Master's thesis). Retrieved from http://www. riss.kr/link?id=T13252933

Kim, M.-S. (1989). A study on the promise of 3-6 years old children (Master's thesis). Retrieved from http://www.riss.kr/ link?id=T889561

Lee, Y. S. (2010). The relationship between mother's parenting style and children's self-regulation. Journal of Emotional \& Behavioral Disorders, 26(3), 63-90.

Moon, I. J. (2008) The relationship between playfulness, fantasymaking predisposition and behavioral self-regulation of 5-yearolds (Master's thesis). Retrieved from http://www.riss.kr/ link?id=T11225639

Son, D.-R. (2004). An action research on the process of making class promise for 4-year-olds (Master's thesis). Retrieved from http://www.riss.kr/link?id=T14727203

Woo, N. H., \& Choi, Y. (2001). The development of an understanding of the notion of promise and changes in promise-keeping behaviors during the preschool years. Korean Journal of Early Childhood Education, 22(4), 355-370.

\section{ORCID}

Ah-Reum Han $\quad$ https://orcid.org/0000-0003-4715-6494

Sae-Young Han http://orcid.org/0000-0001-8207-5927

Received December 30, 2020

Revision received January 26, 2021

Accepted February 8, 2021 